\title{
Base Excision Repair Inhibition by Methoxyamine Impairs Growth and Sensitizes Osteosarcoma Cells to Conventional Treatments
}

\author{
Ana Paula Montaldi1 ${ }^{*}$, Julia Alejandra Pezuk ${ }^{*}$, Elza Tiemi Sakamoto-Hojo², \\ Luiz Gonzaga Tone ${ }^{3}$, María Sol Brassesco ${ }^{2 \#}$ \\ ${ }^{1}$ Department of Genetics, Faculty of Medicine of Ribeirão Preto, University of São Paulo, São Paulo, Brazil \\ ${ }^{2}$ Department of Biology, Faculty of Philosophy, Sciences and Letters at Ribeirão Preto, University of São Paulo, \\ São Paulo, Brazil \\ ${ }^{3}$ Department of Pediatrics, Faculty of Medicine of Ribeirão Preto, University of São Paulo, São Paulo, Brazil \\ Email: ${ }^{\#}$ solbrassesco@usp.br
}

Received 14 January 2014; revised 10 February 2014; accepted 18 February 2014

Copyright (C) 2014 by authors and Scientific Research Publishing Inc.

This work is licensed under the Creative Commons Attribution International License (CC BY).

http://creativecommons.org/licenses/by/4.0/

(c) (i) Open Access

\section{Abstract}

The outcome of patients with osteosarcoma has not significantly improved in the last three decades. Therefore, there is still a need for the development of more effective therapeutic strategies. Methoxyamine (MX) is a base excision repair (BER) inhibitor that has shown anticancer potential by sensitizing a variety of tumor cells to ionizing radiation and chemotherapeutic drugs. In the present study, the in vitro antiproliferative effects of MX were evaluated in two osteosarcoma cell lines, HOS and MG-63. Evaluation of the influence on radiosensitivity and drug interactions in simultaneous treatments with methotrexate, doxorubicin, and cisplatin was also performed. Exposure to MX significantly decreased cell proliferation and mediated a substantial increase of apoptosis. Moreover, our results showed that MX synergized with ionizing radiation in both cell lines while potentiated the antitumor effects of cisplatin and methotrexate. Altogether, the results presented herein demonstrate the feasibility of inhibiting the BER pathway, which may in future be a promising strategy for overcoming intrinsic tumor resistance and to improve the outcome of patients with osteosarcoma.

\section{Keywords}

Osteosarcoma, Methoxyamine, BER, Cell Lines

\footnotetext{
*Montaldi AP and Pezuk JA contributed equally to the senior authorship of this manuscript.

\#Corresponding author.
}

How to cite this paper: Montaldi, A.P., et al. (2014) Base Excision Repair Inhibition by Methoxyamine Impairs Growth and Sensitizes Osteosarcoma Cells to Conventional Treatments. Journal of Cancer Therapy, 5, 307-314. 


\section{Introduction}

Osteosarcoma (OS) is the most common malignant bone tumor that affects children and young adults [1]. The current standard treatment consists of combined chemotherapy with high doses of cisplatin, doxorubicin, and methotrexate, followed by surgical ablation and subsequent rounds of neoadjuvant chemotherapy. Radiotherapy, on the other hand, is indicated only in patients who suffer from inoperable tumors, painful bone metastases or those who refuse surgery.

Despite the advances attained, the improvement of cure rates has not significantly changed over the last 30 years, with long-term survival achieved in only 60\% - 70\% of all patients. OS treatment outcome is often hampered by the tumor's properties of metastasis and subsequent recurrence, with lung metastases as the major cause of death in these patients [2]. Consequently, there is still a relentless pursuit for novel chemotherapeutic agents to prevent osteosarcoma disease progression, improve efficacy and to attenuate toxicity.

On this regard, inhibition of DNA repair pathways has recently presented itself as a new and growing concept intended to sensitize chemo- and radioresistant tumors such as OS. Methoxyamine (MX) is a small organic amine that inhibits DNA base-excision-repair (BER) by tightly interacting with the DNA apurinic/apymidinic (AP) sites (produced through the removal of alkylated or abnormal nucleotides by DNA glycosylases) and promoting increases in single- and double-strand breaks (DSB) that lead to cell death [3].

Chemical inhibition of BER by MX has shown to be a valid pharmacologic strategy to potentiate the cytotoxicity of chemotherapeutic agents in colon cancer [4], ovarian cancer [5] and glioblastoma [6]. Moreover, pretreatment with MX has shown to induce cell cycle arrest and to radiosensitize human colorectal carcinoma cells in vitro [7].

On the basis of these findings, we aimed to test the in vitro antiproliferative effects of MX in two osteosarcoma cell lines, HOS and MG-63, and whether it enhanced the cytotoxicity of other commonly used chemotherapeutic agents.

\section{Methods}

\subsection{Cell Culture}

The human osteosarcoma cell lines HOS and MG-63 were provided by Dr. Jeremy A. Squire (Department of Pathology and Molecular Medicine, Kingston General Hospital, Queen’s University, Kingston, Ontario, Canada). The normal fibroblast cell lines NIH/T3T (murine) and MRC-5 (human) were purchased from ATCC (American Type Culture Collection). Cells were cultured in HAM F10 (Gibco BRL, Life Technologies ${ }^{\circledR}$, Carlsbad, CA, USA) supplemented with $10 \%$ fetal bovine serum, penicillin $(100 \mathrm{U} / \mathrm{mL})$ and streptomycin (100 $\mathrm{ug} / \mathrm{mL}$ ) at $37^{\circ} \mathrm{C}$ in a humidified $5 \% \mathrm{CO}_{2}$ incubator.

\subsection{Drug and Treatments}

Methoxyamine hydrochloride (MX, purity 98\%) was purchased from Sigma-Aldrich (St. Louis, MO, USA) (Catalog \#226904) and diluted in sterile water ( $\mathrm{pH}$ 7.4) according to the manufacturer's instructions. For all experiments, cells were treated with concentrations ranging from 0.75 to $15 \mathrm{mM}$. For combinatorial treatments Cisplatin (CDDP), Methotrexate (MTX) and Doxorrubicin (DXR) were also purchased from Sigma-Aldrich ${ }^{\circledR}$ (Catalog \# C2210000, M9929 and D1515) and diluted in DMSO or in 0.9\% NaCl accordingly.

\subsection{Measurement of Cell Growth by XTT Cell Proliferation Assay}

Cell survival was assessed using the XTT assay (XTT II; Roche Molecular Biochemicals, Catalog \#11465015001). Briefly, equal amounts of cells were seeded in 96-well flat-bottom plates (2500 cells/well) and allowed to attach. Subsequently, cells were treated with different concentrations of MX, or combinations with CDDP, MTX and DXR, incubated for 24, 48 and $72 \mathrm{~h}$. After treatment, the culture medium was removed and replaced with medium containing $10 \mu \mathrm{L}$ of XTT dye $(3 \mathrm{mg} / \mathrm{mL})$ in each well. The plates were incubated for $2 \mathrm{~h}$ at $37^{\circ} \mathrm{C}$ and results interpreted by using an iMarkmicroplate reader (Bio-Rad Laboratories ${ }^{\circledR}$ ). Each experiment was performed in triplicate wells and repeated in three sets of tests.

\subsection{Detection of Apoptotic Cells}

Apoptotic cell death was determined by labeling with annexin V fluorescein isothiocyanate (BD Biosciences 
Pharmigen, San Jose, California, USA). Briefly, $3 \times 10^{2}$ cells were seeded on 6 -well plates containing $3 \mathrm{~mL}$ of culture medium. After 24 hours, the medium was replaced and cells treated with the different concentrations of MX and cultured for additional $48 \mathrm{~h}$. Cells were then trypsinized and centrifuged at $1000 \mathrm{rpm}$ for $5 \mathrm{~min}$ at $4^{\circ} \mathrm{C}$, washed twice with ice-cold PBS, and then $2 \times 10^{5}$ cells were resuspended in $300 \mu \mathrm{l}$ of $1 \times$ annexin $\mathrm{V}$ binding buffer (BD Biosciences Pharmigen, San Diego, California, USA). Cells were stained with $5 \mu \mathrm{l}$ annexin V fluorescein isothiocyanate and $50 \mu \mathrm{l}$ of a solution of $50 \mu \mathrm{mol} / \mathrm{L}$ propidium iodide, and immediately read (10,000 events) by using a BD FACSCalibur flow cytometer (BD Biosciences Pharmigen). Assays were performed three times on separate occasions.

\subsection{Cell Irradiation}

To test the effect of MX on radioresistance clonogenic assays were performed. After tripsinization, single cell suspensions of 500 cells were seeded in six-well plates and allowed to attach for 24 hours. Then, cells were treated with MX $7.5 \mathrm{mM}$ for 2 hours, and then irradiated with final doses of 2, 4, and 6 Gy in single fraction. The RS 2000 X-ray Biological Irradiator (Rad Source Technologies, Inc., Suwanee, GA) was run at $200 \mathrm{kVp}$ and $25 \mathrm{~mA}$ with its standard $0.3 \mathrm{~mm}$ of $\mathrm{Cu}$ filtration. The X-ray generated under this condition had an energy spectrum with the minimum energy of $95 \mathrm{kV}$ up to maximum $200 \mathrm{kV}$, and the half value of the beam was 0.62 $\mathrm{mm}$ of $\mathrm{Cu}$. The dose gradient of this X-ray in tissue-equivalent bolus was about $-10 \%$ per $0.5 \mathrm{~cm}$ depth. The plates were aligned equidistant from the beam center and within the cone to ensure a uniform dose-rate (approximately $2.85 \mathrm{~Gy} /$ minute) and total dose delivery per fraction. Quality assurance was performed using nanoDot dosimeters (Landauer, Inc., Glenwood, IL). Dose readings at plate surface were used to calculate the appropriate "beam-on" treatment times. Dosimeters were placed below the plates undergoing treatment and were compared to the doses in the planning.

After irradiation cell cultures were further incubated for 22 hours with MX and then the culture medium replaced with drug-free media and cultivated for 7 days and colonies analyzed as described above. Radiation dose enhancement ratios (DER) by MX were calculated using the following formula: DER = (surviving fraction at an indicated dose of radiation alone)/(surviving fraction at an indicated dose of radiation $+\mathrm{MX}$ ). DER $=1$ suggests an additive radiation effect and DER $>1$, a supra-additive effect as against a sub-additive effect in the case of DER $<1$.

\subsection{Statistical Analysis}

Statistical analyses were performed by using the Sigma Stat software (Jandel Scientific Company). Two Way Repeated Measures Analysis of Variance (ANOVA) followed by the Holm-Sidak Pairwise Multiple Comparison was used to establish whether significant differences existed between groups. All tests were carried out for $\alpha$ $=0.05$. Effective concentrations $\left(\mathrm{IC}_{50}\right)$ were analyzed using the CalcuSyn software v2.0 (Biosoft, Cambridge, UK). This program provides a measure of the combined drug interaction by the generation of a combination index (CI) value. The CI value is based on the multiple drug-effect equation of Chou and Talalay [8] and defines the drug interactions as synergistic $\mathrm{CI}$ value $<1$, CI value $=1$ for additive, and CI value $>1$ for antagonism. Calcusyn $^{\circledast}$ software was also used to calculate the dose reduction index (DRI) of drug combinations which estimates the extent to which the dose of one or more agents in the combination can be reduced to achieve effect levels that are comparable with those achieved with single agents.

\section{Results}

\subsection{Impairs Growth in HOS and MG-63 Cell Lines}

MX significantly inhibited growth in both osteosarcoma cell lines when compared to control at all concentrations and times tested ( $<$ 0.05) (Figure 1(a)), though growth abrogation was neither time- nor concentration-dependent. For HOS cells, proliferation was reduced in about $75 \%$ at concentrations ranging from 0.75 to $7.5 \mathrm{mM}$ and $85 \%$ after treatment with $15 \mathrm{mM}$. MG-63 on the other hand, showed a reduction of about $60 \%$ after treatment with lower concentrations for 24 and $48 \mathrm{~h}$, though after $72 \mathrm{~h}$ growth impairment was inferior reaching about 55\% for lower concentrations and a maximum of $73 \%$ after treatment with MX $15 \mathrm{mM}$. IC 50 values after $72 \mathrm{~h}$ of treatment were determined as 2.29 and 15.78 for HOS and MG-63, respectively (Table 1). On the other hand, even after $72 \mathrm{~h}$ of incubation, MX did not affect cell viability of both normal fibroblast cell lines, MRC-5 


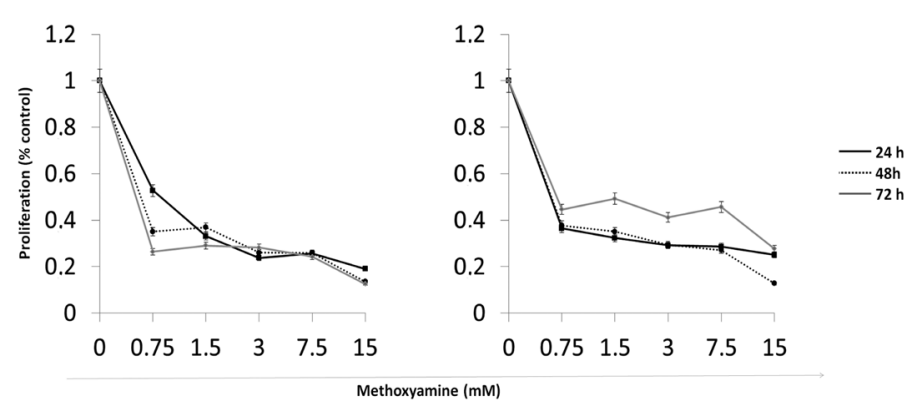

(a)

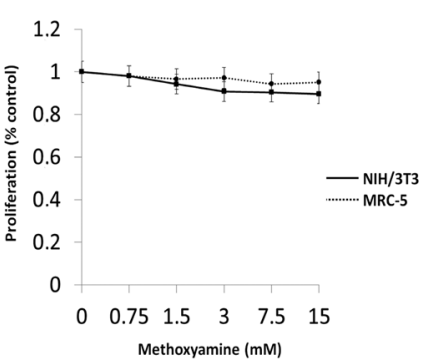

(b)

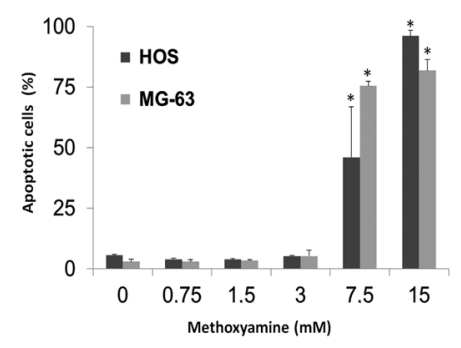

(c)

Figure 1. (a) Characterization of the effects of BER inhibition on cell growth in HOS (left) and MG-63 (right) osteosarcoma cell lines as detected by the $\mathrm{XTT}^{\circledR}$ assay after 24, 48 and $72 \mathrm{~h}$ of treatment; (b) Even after long exposure (72 h) MX did not affect the viability of normal fibroblasts; (c) BER inhibition by MX induced a significant increase in apoptosis rates. Each point represents the mean \pm SD of triplicate independent assays.

Table 1. Doses required to induce $50 \%$ inhibition of cell growth $\left(\mathrm{IC}_{50}\right)$ in osteosarcoma cell lines after $72 \mathrm{~h}$ of treatment.

\begin{tabular}{ccc}
\hline & \multicolumn{2}{c}{ IC $_{\mathbf{5 0}}$ values } \\
\hline Drug & HOS & MG-63 \\
\hline MX $(\mathrm{mM})$ & 2.29 & 15.78 \\
CDDP $(\mu \mathrm{g} / \mathrm{ml})$ & 5.07 & 4.99 \\
MTX $(\mu \mathrm{M})$ & 6.38 & 23.87 \\
DXR $(\mu \mathrm{M})$ & 0.78 & 0.20 \\
\hline
\end{tabular}

and NIH/3T3 (Figure 1(b)).

\subsection{Induces Apoptosis in Osteosarcoma Cells}

Compared to control, MX treatment of both OS cell lines mediated a significant increase of apoptosis after treatment with MX 7.5 and $15 \mathrm{mM}$ for $72 \mathrm{~h}(\mathrm{p}<0.05$ ) (Figure 1(c)). Maximum apoptosis corresponded with 96\% and $81 \%$ for HOS and MG-63 cells after treatment with the highest concentration.

\subsection{Methoxyamine Enhances the Cytotoxicity of Commonly Used Drugs: CDDP and MTX}

To study the cytotoxic effects of MX in association with commonly used drugs, HOS and MG-63 cells were simultaneously treated with MX $7.5 \mathrm{mM}$ and different concentrations of CDDP, DXR and MTX. Our results showed synergistic effects (CI > 1) when the BER inhibitor was combined with CDDP and MTX, though it did not sensitize the osteosarcoma cells to DXR (Table 2). Sensitization of HOS cells only occurred at the highest 
Table 2. Median dose effect analysis was also employed to characterize the interactions between MX with CDDP. MTX or DXR. Combination index (CI) values $<1$ correspond to a synergistic interaction (highlighted in grey). $\mathrm{CI}>1$ denotes antagonistic effects. Dose reduction index (DRI) reflects the fold reduction in the required concentration of tested agents when used in combination to achieve the comparable affected fraction (AF).

\begin{tabular}{|c|c|c|c|c|c|c|c|}
\hline \multirow{2}{*}{\multicolumn{2}{|c|}{ MX 7.5 mM with: }} & \multicolumn{3}{|c|}{ HOS } & \multicolumn{3}{|c|}{ MG-63 } \\
\hline & & AF & CI & DRI & AF & CI & DRI \\
\hline \multirow{4}{*}{ CDDP } & $0.04 \mu \mathrm{g} / \mathrm{ml}$ & 0.39 & 13.66 & 7.45 & 0.39 & 0.59 & 17.68 \\
\hline & $0.08 \mu \mathrm{g} / \mathrm{ml}$ & 0.51 & 2.99 & 6.67 & 0.51 & 0.68 & 7.81 \\
\hline & $0.16 \mu \mathrm{g} / \mathrm{ml}$ & 0.47 & 5.05 & 2.76 & 0.47 & 0.62 & 6.53 \\
\hline & $0.32 \mu \mathrm{g} / \mathrm{ml}$ & 0.76 & 0.19 & 7.17 & 0.76 & 0.85 & 2.76 \\
\hline \multirow{3}{*}{ MTX } & $4 \mu \mathrm{M}$ & 0.30 & 58.19 & 0.32 & 0.29 & 2.25 & 0.62 \\
\hline & $8 \mu \mathrm{M}$ & 0.49 & 4.95 & 0.75 & 0.46 & 1.45 & 1.05 \\
\hline & $16 \mu \mathrm{M}$ & 0.48 & 7.15 & 0.34 & 0.51 & 0.73 & 3.62 \\
\hline \multirow{5}{*}{ DXR } & $32 \mu \mathrm{M}$ & 0.75 & 0.65 & 1.71 & 0.72 & 0.44 & 8.71 \\
\hline & $5 \mu \mathrm{M}$ & 0.36 & 38.86 & 0.06 & 0.54 & 14.97 & 0.06 \\
\hline & $10 \mu \mathrm{M}$ & 0.47 & 19.74 & 0.07 & 0.54 & 28.97 & 0.03 \\
\hline & $20 \mu \mathrm{M}$ & 0.48 & 31.07 & 0.03 & 0.57 & 38.00 & 0.02 \\
\hline & $40 \mu \mathrm{M}$ & 0.75 & 8.10 & 0.12 & 0.77 & 3.60 & 0.30 \\
\hline
\end{tabular}

concentrations of both drugs.

\subsection{Sensitizes Cells to Ionizing Radiation}

To study the cytotoxic effects of MX in association with $\gamma$-radiation, HOS and MG-63 cells were incubated for 2 hours with $7.5 \mathrm{mM}$ of the drug. Then, cells were irradiated with final doses of 2, 4, and 6 Gy and incubated with the drug for additional 22 hours. The culture medium was replaced and cells reincubated in the absence of drug until colonies were formed. The results showed that MX treatment led to radiosensitization for the HOS cell line showing supra-additive effects at all doses tested (Table 3). In the case of MG-63, potentialization of radiation effects were observed for lower doses (2 and 4 Gy) (Table 3).

\section{Discussion}

Intrinsic or acquired drug resistance is the common cause of treatment failure in OS. Over the last decade, new insights of the impact of DNA repair pathways on anticancer therapy have yielded promising expectations to improve treatment efficacy. In an ideal scenario, exposure to cytotoxic DNA damaging agents along with the blockage of DNA repair would produce a synergistic effect, and hence significantly increase tumor cell killing.

BER is an important drug-resistance factor because of the variety of substrates and its ability to rapidly and efficiently repair DNA lesions [9] [10]. Several antisense and RNA interference studies have shown that downregulation of its components sensitizes cells to various anticancer agents [11]-[15]. Knocking down Ape1 expression in human osteosarcoma cells by siRNA, for example, significantly enhanced cell sensitivity to methyl methanesulfonate, $\mathrm{H}_{2} \mathrm{O}_{2}$, ionizing radiation, thiotepa and etoposide [4] [16].

Thus, on the basis of these findings, we investigated the antiproliferative effects of the pharmacological inhibition of the BER pathway by MX and whether it enhanced the therapeutic efficacy of agents routinely used in the initial therapy of OS (CDDP, MTX, and DXR) and radiotherapy. Our results showed that treatment with MX not only inhibited proliferation and induced apoptosis in OS cells when used alone, but also potentiated the antitumor effects of radiation, CDDP and MTX in both cell lines. Previous reports have shown that this alkoxyamine derivative potentiates the cytotoxic effect of antimetabolites and alkylating agents [6] by binding to apurinic/pyrimidinic (AP) sites in DNA, what blocks the function of the downstream proteins Ape1/Ref- 1 and $\beta$ polymerase, interrupting the BER repair pathway and ensuing cell death. 
Table 3. Dose enhancement ratios for osteosarcoma cell lines treated with MX $7.5 \mathrm{~mm}$ analyzed through clonogenic assay

\begin{tabular}{cccc}
\hline & \multicolumn{3}{c}{ Cell line } \\
\hline & & HOS & MG-63 \\
\hline & $\mathbf{2 ~ G y}$ & 1.41 & 1.32 \\
& $\mathbf{4}$ Gy & 1.51 & 1.05 \\
& $\mathbf{6 ~ G y}$ & 2.14 & 0.94 \\
\hline
\end{tabular}

Commonly, OS tumors show intrinsic resistance and respond poorly to preoperative chemotherapy based on MTX, CDDP and DXR. Previous reports have shown that the MG-63 cell line studied herein is resistant to such drugs [17]. So far, several mechanisms have been proposed to explain drug resistance in OS (i.e. p-glycoprotein and multidrug resistance genes overexpression) [18], though little has been accurately recognized as a factual negative contributor upon therapeutic efficacy. Remarkably, high APE1 protein levels have been found in more than $70 \%$ of OS with a significant correlation with reduced survival times [16], suggesting that the BER pathway may also play an important role assisting OS resistance and prognosis.

Exposure to CDDP yields different types of DNA damage, among which, interstrand cross-links completely block transcription and replication, and, as a result, are lethal to the cell. Compelling evidence suggests a possible role of BER in cross-links repair [19] [20]. More interestingly, APE1 over expression have been associated with CDDP resistance in other tumors [21] and in accordance with our results, it has been shown that targeting BER enhances sensitivity to CDDP and other cross-linking agents such asmitomycin C and psoralenin human cells [22] [23]. Conversely, nucleotide depletion by MTX also affects the ability of cells to carry out the excision repair of DNA damage [24], what might also enhance the effect of MX and explain the synergistic effects that were observed. Moreover, even though MX was unable to sensitize OS cells to DXR, a recent study by Guerreiro et al., [25] demonstrated that while not affecting viability this drug promotes chromosomal damage in DXR-treated breast cancer cells.

The use of radiotherapy in OS treatment, on the other hand, is debatable because of intrinsic radioresistance. Nevertheless, its administration may influence prognosis as local treatment of unresectable tumors, or as palliation of symptomatic metastases [26]. Although double-strand breaks (considered the most lethal type of ionizing radiation-DNA damage) are mainly repaired by nonhomologous end joining and homologous recombination repair pathways, other lesions induced by direct DNA hits or the generation of reactive $\mathrm{O}_{2}$ species may lead to single-strand breaks or oxidized bases (i.e. 8-oxo-G) that are also recognized and processed by BER [27]. Our results also show that inhibition of this repair pathway by MX can intensify the cytotoxicity of radiation at low doses in OS, what might lower effective therapeutic doses and prevent adverse side effects in patients.

In addition to all the in vitro preclinical data that confirm that modulation of BER by MX is associated with enhanced sensitivity to both ionizing radiation and chemotherapy [3], no systemic toxicity has been noticed in mice exposed to this drug [4]. Moreover, a Phase I clinical trial of MXin combination with Temozolamide has been initiated and seems to be well tolerated [28].

\section{Conclusion}

The survival of patients with OS has not improved significantly in recent years. Still, one third of patients remain at high risk of relapse and adverse outcome. The results presented herein demonstrate the feasibility of inhibiting the BER pathway by using MX, which may in future be a promising strategy for overcoming intrinsic tumor resistance and to advance the treatment of this cancer.

\section{Conflict of Interest}

The authors declare none.

\section{References}

[1] Raymond, A.K., Ayala, A.G. and Knuutila, S. (2002) Conventional Osteosarcoma. In: Fletcher, C.D.M., Unni, K.K. and Mertens, F. (Eds.), Pathology and Genetics of Tumours of Soft Tissue and Bone. World Health Organization Clas- 
sification of Tumours. IARC Press, Lyon.

[2] Jaffe, N. (2009) Osteosarcoma: Review of the Past, Impact on the Future. The American Experience. Cancer Treatment and Research, 152, 239-262. http://dx.doi.org/10.1007/978-1-4419-0284-9_12

[3] Liu, L. and Gerson, S.L. (2004) Therapeutic Impact of Methoxyamine: Blocking Repair of Abasic Sites in the Base Excision Repair Pathway. Current Opinion in Investigational Drugs, 5, 623-627.

[4] Liu, L., Nakatsuru, Y. and Gerson, S.L. (2002) Base Excision Repair as a Therapeutic Target in Colon Cancer. Clinical Cancer Research, 8, 2985-2991.

[5] Fishel, M.L., He, Y., Smith, M.L., et al. (2007) Manipulation of Base Excision Repair to Sensitize Ovarian Cancer Cells to Alkylating Agent Temozolomide. Clinical Cancer Research, 13, 260-267. http://dx.doi.org/10.1158/1078-0432.CCR-06-1920

[6] Montaldi, A.P. and Sakamoto-Hojo, E.T. (2013) Methoxyamine Sensitizes the Resistant Glioblastoma T98G Cell Line to the Alkylating Agent Temozolomide. Clinical and Experimental Medicine, 13, 279-288. http://dx.doi.org/10.1007/s10238-012-0201-x

[7] Yan, T., Seo, Y., Schupp, J.E., et al. (2006) Methoxyamine Potentiates Iododeoxyuridine-Induced Radiosensitization by Altering Cell Cycle Kinetics and Enhancing Senescence. Molecular Cancer Therapeutics, 5, 893-902. http://dx.doi.org/10.1158/1535-7163.MCT-05-0364

[8] Chou, T.C. and Talalay, P. (1984) Quantitative Analysis of Dose-Effect Relationships: The Combined Effects of Multiple Drugs or Enzyme Inhibitors. Advances in Enzyme Regulation, 22, 27-55. http://dx.doi.org/10.1016/0065-2571(84)90007-4

[9] Loeb, L.A. (1985) Apurinic Sites as Mutagenic Intermediates. Cell, 40, 483-484. http://dx.doi.org/10.1016/0092-8674(85)90191-6

[10] Krokan, H.E., Standal, R. and Slupphaug, G. (1997) DNA Glycosylases in the Base Excision Repair of DNA. Biochemical Journal, 325, 1-16.

[11] Boiteux, S. and Guillet, M. (2004) Abasic Sites in DNA: Repair and Biological Consequences in Saccharomyces cerevisiae. DNA Repair (Amst), 3, 1-12. http://dx.doi.org/10.1016/j.dnarep.2003.10.002

[12] Hu, H.Y., Horton, J.K., Gryk, M.R., et al. (2004) Identification of Small Molecule Synthetic Inhibitors of DNA Polymerase Beta by NMR Chemical Shift Mapping. Journal of Biological Chemistry, 279, 39736-39744. http://dx.doi.org/10.1074/jbc.M402842200

[13] Naidu, M.D., Mason, J.M., Pica, R.V., et al. (2010) Radiation Resistance in Glioma Cells Determined by DNA Damage Repair Activity of Ape1/Ref-1. Journal of Radiation Research, 51, 393-404. http://dx.doi.org/10.1269/jrr.09077

[14] Xiong, G.S., Sun, H.L., Wu, S.M., et al. (2010) Small Interfering RNA against the Apurinic or Apyrimidinic Endonuclease Enhances the Sensitivity of Human Pancreatic Cancer Cells to Gemcitabine in Vitro. Journal of Digestive Diseases, 11, 224-230.

[15] Chen, S., Xiong, G., Wu, S., et al. (2013) Downregulation of Apurinic/Apyrimidinic Endonuclease 1/Redox Factor-1 Enhances the Sensitivity of Human Pancreatic Cancer Cells to Radiotherapy in Vitro. Cancer Biotherapy and Radiopharmaceuticals, 28, 169-176. http://dx.doi.org/10.1089/cbr.2012.1266

[16] Wang, D., Luo, M. and Kelley, M.R. (2004) Human Apurinic Endonuclease 1 (APE1) Expression and Prognostic Significance in Osteosarcoma: Enhanced Sensitivity of Osteosarcoma to DNA Damaging Agents Using Silencing RNA APE1 Expression Inhibition. Molecular Cancer Therapeutics, 3, 679-686.

[17] Decker, S., Winkelmann, W., Nies, B., et al. (1999) Cytotoxic Effect of Methotrexate and Its Solvent on Osteosarcoma Cells in Vitro. The Journal of Bone \& Joint Surgery (British Volume), 81, 545-551. http://dx.doi.org/10.1302/0301-620X.81B3.9167

[18] Brambilla, D., Zamboni, S., Federici, C., et al. (2012) P-Glycoprotein Binds to Ezrin at Amino Acid Residues 149-242 in the FERM Domain and Plays a Key Role in the Multidrug Resistance of Human Osteosarcoma. International Journal of Cancer, 130, 2824-2834. http://dx.doi.org/10.1002/ijc.26285

[19] Wilson III, D.M. and Seidman, M.M. (2010) A Novel Link to Base Excision Repair? Trends in Biochemical Sciences, 35, 247-252. http://dx.doi.org/10.1016/j.tibs.2010.01.003

[20] Wang, D., Xiang, D.B., Yang, X.Q., et al. (2009) APE1 Overexpression Is Associated with Cisplatin Resistance in Non-Small Cell Lung Cancer and Targeted Inhibition of APE1 Enhances the Activity of Cisplatin in A549 Cells. Lung Cancer, 66, 298-304. http://dx.doi.org/10.1016/j.lungcan.2009.02.019

[21] Kothandapani, A., Dangeti, V.S., Brown, A.R., et al. (2011) Novel Role of Base Excision Repair in Mediating Cisplatin Cytotoxicity. Journal of Biological Chemistry, 286, 14564-14574. http://dx.doi.org/10.1074/jbc.M111.225375

[22] Couve-Privat, S., Mace, G., Rosselli, F., et al. (2007) Psoralen-Induced DNA Adducts Are Substrates for the Base Excision Repair Pathway in Human Cells. Nucleic Acids Research, 35, 5672-5682. http://dx.doi.org/10.1093/nar/gkm592 
[23] Allan, J.M., Engelward, B.P., Dreslin, A.J., et al. (1998) Mammalian 3-Methyladenine DNA Glycosylase Protects against the Toxicity and Clastogenicity of Certain Chemotherapeutic DNA Cross-Linking Agents. Cancer Research, 58, 3965-3973.

[24] Borchers, A.H., Kennedy, K.A. and Straw, J.A. (1990) Inhibition of DNA Excision Repair by Methotrexate in Chinese Hamster Ovary Cells Following Exposure to Ultraviolet Irradiation or Ethylmethanesulfonate. Cancer Research, 50, 1786-1789.

[25] Guerreiro, P.S., Fernandes, A.S., Costa, J.G., et al. (2013) Differential Effects of Methoxyamine on Doxorubicin Cytotoxicity and Genotoxicity in MDA-MB-231 Human Breast Cancer Cells. Mutation Research, 757, 140-147. http://dx.doi.org/10.1016/j.mrgentox.2013.08.003

[26] Ozaki, T., Flege, S., Kevric, M., et al. (2003) Osteosarcoma of the Pelvis: Experience of the Cooperative Osteosarcoma Study Group. Journal of Clinical Oncology, 21, 334-341. http://dx.doi.org/10.1200/JCO.2003.01.142

[27] Kinsella, T.J. (2009) Coordination of DNA Mismatch Repair and Base Excision Repair Processing of Chemotherapy and Radiation Damage for Targeting Resistant Cancers. Clinical Cancer Research, 15, 1853-1859. http://dx.doi.org/10.1158/1078-0432.CCR-08-1307

[28] Savvides, P., Xu, Y., Liu, L., et al. (2010) Pharmacokinetic Profile of the Base-Excision Repair Inhibitor Methoxyamine-HCl (TRC102; MX) Given as an One-Hour Intravenous Infusion with Temozolomide (TMZ) in the First-inHuman Phase I Clinical Trial. Journal of Clinical Oncology, 28, Article ID: e13662. 